\title{
A postura docente e os ciclos de aprendizagem em São Paulo
}

\author{
Teachers' posture and learning cycles in São Paulo
}

\section{Isabel Bilecki da Cunha ${ }^{1}$}

\section{RESUMO:}

A partir da análise de pesquisas sobre as propostas de ciclos e progressão continuada no Brasil, foi realizado um estudo de caso em uma escola da rede pública municipal de São Paulo ao longo do ano letivo de 2006. Esta pesquisa teve como objetivo revelar a postura dos docentes a partir de suas práticas e das reflexões que fazem sobre seu trabalho, inserido num contexto de ciclos. O trabalho de campo realizou-se por meio de observação participante, análise documental e de entrevistas semiestruturadas com sete professoras do primeiro ciclo do ensino fundamental. Verificouse que os docentes, a despeito de serem em geral contrários à proposta, têm ao longo dos anos mudado a postura em relação aos alunos diante das novas realidades criadas pelos ciclos, reconstruindo suas práticas como forma de adaptar antigas concepções de ensino à estrutura que foi gerada. Essas mudanças partem da necessidade de atender aos alunos com dificuldades de aprendizagem, incluídos no sistema de ensino a partir da implantação do regime de ciclos. A análise revela que as condições de trabalho não têm contemplado demandas importantes como a formação docente, a participação da comunidade escolar, a articulação do trabalho coletivo e a criação de instrumentos de apoio aos alunos nos diferentes anos do ensino fundamental.

PALAVRAS-CHAVE: Ciclos; trabalho docente; educação pública; ensino fundamental; políticas públicas.

\begin{abstract}
:
According torecentstudiesontheperformance of learning cycles with age promotion in Brazil, the present research carried out a case study in a school of Sao Paulo municipal public system during the 2006 academic year. This research aimed to reveal the teacher's posture through the observation of their practices and by the dialogue with teachers about their work on learning cycles. The field work included participant observation, documental analysis and performance of semistructured interviews with seven teachers of ensino fundamental I (elementary level). It was verified that, in spite of refusing official proposal, teachers have reconstructed practices as a way to adapt old teaching concepts to the new created structure. These changes intended to provide teacher with tools for dealing with students on difficulty which have being included in school by the implementation of learning cycles. The analysis reveals that the teachers' working conditions do not satisfy important demands as teachers' education, school community participation, articulation of collective work and the creation of supportive tools for the students in the elementary level.
\end{abstract}

KEYWORDS: cycles; teachers' working; public education; elementary school; public policies. 


\section{Introdução}

Estudos acerca dos processos de implantação de políticas de não-retenção no Brasil a partir dos anos 50 revelam a importância da adesão docente para a efetivação dos objetivos propostos em cada rede de ensino (MAINARDES, 1998; VASCONCELLOS; 1999). Também se constata que muitos projetos não proporcionaram os encaminhamentos necessários para sua implementação, como o envolvimento dos profissionais na elaboração das propostas, amplas oportunidades de capacitação docente ao longo do processo e melhores condições de trabalho para $\mathrm{O}$ atendimento de alunos com diferentes ritmos de aprendizagem (VASCONCELLOS, 1999; FREITAS, 2000). Considerando as críticas tecidas sobre a ineficácia de diferentes redes de ensino no momento e ao longo dos processos de implantação desses regimes, responsabiliza-se, na maioria dos casos, o professor pela não efetivação de mudanças nas práticas pedagógicas adotadas nas escolas (SENA e MEDEIROS, 1984; AMBROSETTI, 1989; ANDRADE, 1992; GUILHERME, 1998). Essas críticas apontam a permanência de práticas que seguem uma linha de ensino mais tradicional como forma de resistência às propostas de ensino não-seriado. Esses estudos afirmam que os docentes não foram convencidos da validade dessas mudanças, não havendo a aceitação necessária para a efetivação dos objetivos das propostas na prática. Assim, não se observou, segundo os estudos, alterações nas metologias usadas pelos professores, fazendo com que as mudanças esperadas não se concretizassem dentro das escolas.

A implantação dos ciclos de aprendizagem na rede pública municipal de São Paulo, a partir de 1992 no governo de Luiza Erundina (Partido dos Trabalhadores, PT), abrangeu o antigo ensino de $1^{\circ}$ grau como um todo. A rede de ensino municipal paulistana sofreu algumas mudanças voltadas à implantação dos ciclos em todas as suas escolas. A regulamentação da proposta de ciclos foi feita por meio de um novo regimento comum das escolas municipais. De acordo com o regimento, o ensino fundamental foi organizado em três ciclos: dois ciclos de três anos e o terceiro ciclo de dois anos com a possibilidade de retenção do aluno ao final de cada ciclo. A partir da gestão de 1997, o ensino fundamental é reorganizado, tendo sido implantados dois ciclos com quatro anos de duração cada.

Nessa linha, a experiência dos ciclos de aprendizagem em São Paulo segue as críticas tecidas sobre outras medidas de reorganização do ensino fundamental no Brasil. Segundo os estudos da área, apesar do propósito de realizar um processo democrático de transição na rede, professores afirmaram não ter participado desse processo e muitos deles desaprovam a forma com que ele foi feito, considerando que os ciclos foram impostos pela administração da época (MAIA; CRUZ; RAMOS, 1995; JACOMINI, 2002). Assim, pesquisas recentes afirmam que a questão da implementação do ensino em ciclos na rede municipal de São Paulo ainda não foi solucionada (JACOMINI, 2002; SILVA, 2004, MACHADO, 2005).

A partir dessa constatação e da avaliação do contexto em que a pesquisa na área se encontra, é possível tecer alguns questionamentos e reflexões acerca da real postura que professores vêm assumindo diante dos ciclos de aprendizagem após mais de uma década de sua implantação na rede pública municipal de São Paulo. As pesquisas feitas, partindo dos problemas relacionados ao processo de implantação dos ciclos, não evidenciam como de fato essa questão é enfrentada atualmente. Também não extraem informações importantes do contexto no qual a ação docente se insere, restringindo-se a estudos históricos e entrevistas isoladas. A partir dessa constatação, percebe-se a necessidade de entender os impactos dos ciclos na prática, sob a perspectica dos próprios docentes.

\section{Metodologia e procedimentos}

A realização da pesquisa qualitativa do tipo etnográfico se deu por meio de um estudo de caso. A escolha por esse método parte da necessidade de extrair da realidade vivenciada por professores de ensino fundamental I, a postura adotada atualmente em relação aos ciclos de aprendizagem na rede pública municipal de São Paulo, foco deste estudo.

Foi escolhida uma escola da rede pública e contou-se com a participação de sete professoras durante o ano letivo de 2006. Nessa escola também atuei como professora do $2^{\circ}$ ano 
do ensino fundamental e participei dos horários coletivos de trabalho, realizei entrevistas com as docentes e a análise de documentos da escola e de materiais de professoras e alunos.

Após a realização do trabalho de campo, iniciou-se o período de análise de dados e confrontamento com a literatura sobre o tema do trabalho docente e ciclos. Posteriormente, tornouse necessário evidenciar os aspectos da prática docente considerados mais relevantes, a fim de facilitar o processo de análise. Relacionando os temas recorrentes e as implicações dos ciclos no contexto analisado, procedeu-se a uma seleção para permitir o aprofundamento daqueles que afetam de forma mais direta a implementação do regime de ciclos e o trabalho docente.

\section{Planejamento curricular}

A partir da análise de estudos sobre ciclos e prática docente é possível constatar a importância do planejamento curricular para a organização do trabalho pedagógico, dando um melhor encaminhamento às atividades propostas a cada nível de ensino, respeitando-se os ritmos e as necessidades individuais de aprendizagem (SACRISTÁN e GÓMES, 1998; PERRENOUD, 2004). Barretto (2007, p. 3) destaca a importância do planejamento curricular inserido no projeto político-pedagógico como forma de delinear os objetivos do ensino em uma estrutura ciclada.

Pelo depoimento das professoras, notase que o conceito de currículo como meio de elaboração coletiva do percurso desejável aos alunos no decorrer de sua escolaridade ainda não foi incorporado por elas. Ao serem questionadas sobre a forma de elaboração do currículo, elas se reportam à grade curricular para exemplificar como trabalham os conteúdos em cada ano do ciclo.

A elaboração do planejamento curricular usualmente acontece em reuniões determinadas pela SME (Secretaria Municipal de Educação) e planejadas dentro de cada escola pelo coordenador pedagógico e demais membros da equipe técnica. Nessas reuniões, os professores costumam ser divididos por ano (série) de acordo com a turma que estão lecionando em dado ano letivo. Concentra-se, assim, a responsabilidade sobre a elaboração do planejamento daquele ano sobre o grupo de professores que vão lecionar para esses alunos. Não existe uma correlação mais direta do que ocorreu no ano anterior, sequer uma avaliação do percurso realizado pelos alunos até aquele momento. Também não se observa o resgate do trabalho desenvolvido pelos demais professores, incluindo as falhas, as limitações e os avanços alcançados.

O processo de seleção de atividades, projetos e conteúdos para o ano letivo segue a percepção individual dos professores do que julgam que seja mais importante para os alunos daquela faixa etária. Existe um esforço no sentido de buscar temas de interesse dos alunos, mas de fato os professores não têm claro quais são suas reais necessidades. Não é realizada uma avaliação mais próxima da comunidade no sentido de encontrar temas que são próprios do seu cotidiano ou do que realmente necessitem aprender. Um conflito interessante é entre a inclusão de temas que parecem fazer parte do cotidiano dos alunos e o tratamento de conteúdos mais gerais como fatos da história do Brasil, algoritmos matemáticos, conceitos de ciência, regras gramaticais etc. Para os docentes, é difícil estabelecer quais são as prioridades do ensino, como dosar os conteúdos universais e os temas da vida cotidiana dos alunos, sem perder de vista a qualidade da educação.

Ao início do ano cabe a cada professor diagnosticar os conhecimentos adquiridos e as dificuldades de sua classe, fazendo as devidas adaptações para que os alunos acompanhem o conteúdo estabelecido ou, se necessário, a reformulação desses conteúdos e objetivos. Isso é feito por meio de sondagens, de exercícios, da observação e do conhecimento que cada professor desenvolve sobre sua classe.

Percebe-se também que a presença de alunos com diferentes níveis de aprendizagem nas classes regulares gera a reformulação do planejamento por parte das professoras. Segundo as docentes não há como ignorá-los, ou manter um planejamento que a turma "não acompanha".

Para as dificuldades mais acentuadas, as professoras buscam atividades diferenciadas e algum tipo de atendimento especial. No entanto, reconhecem que é difícil elaborar um planejamento adequado a esses alunos e que 
esse atendimento é feito em meio às dificuldades cotidianas, monstrando-se falho.

Apesar dos problemas encontrados, notamse avanços na fala das professoras no sentido de adaptarem suas práticas e disporem tempo para propor atividades que vão ao encontro da necessidade dos alunos em cada ano dos ciclos. Percebe-se que uma visão de planejamento fechado e que privilegia o tratamento de conteúdos foi se adaptando com o surgimento de dificuldades não vivenciadas anteoriormente, no regime seriado. Um currículo mais eficiente e apropriado aos alunos e suas particularidades ainda não é atingido, mas o caminho traçado até o momento indica avanços importantes para essa transformação.

\section{Trabalho coletivo}

A adoção do regime de ciclos prevê uma maior flexibilização dos tempos e espaços escolares como meio de proporcionar aos alunos condições favoráveis para seu desenvolvimento. Nesse sentido, o trabalho coletivo mostra-se essencial para atingir os objetivos propostos ao ensino em ciclos, pois é por meio dele que a escola terá condições de promover a articulação necessária entre os seus membros, dando sentido e propósito à ação educativa.

Um legado ainda presente do regime seriado nas escolas regulares é a fragmentação do trabalho docente, sendo cada professor responsável pelo desenvolvimento de "sua" turma. Assim, a cada ano letivo, um novo professor dá continuidade ao trabalho, seguindo um planejamento que ele espera que os alunos acompanhem, considerando o nível de ensino correspondente e fazendo as alterações que julgar necessárias.

A fragmentação tratada no tema anterior representa uma barreira para que a comunidade escolar como um todo consiga realizar um trabalho mais integrado, por meio de uma maior comunicação entre seus membros. A divisão entre turnos, horários coletivos, e professores de cada ciclo é um fator importante na compreensão dessa problemática.

Desde a gestão que implantou os ciclos na rede municipal de São Paulo foram instituídas novas jornadas de trabalho, incluindo-se em algumas delas a possibilidade de formação de grupos para o trabalho coletivo. O objetivo principal desses grupos é a criação de projetos especiais de ação, contando com a orientação do coordenador pedagógico. O que se nota, no entanto, é que a realização desses horários tem sido marcada pelo tratamento de temas propostos pela coordenadoria de ensino e de ações burocráticas, como o preenchimento de relatórios e fichas para a pontuação dos professores participantes.

Muitos encontros não eram orientados, já que demais atribuições da coordenadora pedagógica impediam que ela estivesse todo o tempo com os professores. Nesses momentos, elas utilizavam esse espaço para a troca de experiências e de materiais. Esses encontros se revelavam ricos como debate e formulação coletiva de soluções e alternativas para as dificuldades enfrentadas pelas professoras.

Observa-se, também, que naturalmente as docentes formam distintos grupos de trabalho que têm, muitas vezes, como ponto de ligação a afinidade entre seus membros. E esses grupos têm servido como importantes alicerces do trabalho docente em ciclos, pois são neles que as professoras conseguem compartilhar experiências e refletir sobre os problemas vivenciados cotidianamente no trabalho com os ritmos de aprendizagem dos alunos, buscando no grupo a possibilidade de formular respostas conjuntas a suas inquietações.

Essa troca de experiências e impressões sobre o processo educativo dos alunos leva ao crescimento profissional das participantes dos grupos, já que contribuem positivamente para que se desenvolvam certas habilidades diante das barreiras encontradas. O trabalho coletivo na escola sempre existiu. O que se busca com os ciclos é que integração entre os profissionais facilite o direcionamento do percurso escolar dos alunos. Apesar de notar avanços nas ações coletivas entre os professores, esse trabalho não pode depender das afinidades pessoais de cada um para a formação de grupos de trabalho. Se houvesse um direcionamento das discussões e de aprofundamento teórico dos conhecimentos construídos, seria possível atingir melhores resultados, levando à construção de novas perspectivas de ensino em ciclos de acordo com as necessidades de cada grupo de alunos e a partir das experiências de seus professores. 


\section{Avaliação}

Mediante os estudos acerca das perspectivas para o ensino em ciclos, nota-se que a avaliação ganha um novo sentido quando inserida em uma estrutura ciclada. Com o objetivo de incluir os alunos considerando seus diferentes ritmos de aprendizagem no sistema de ensino, o modelo de avaliação mais tradicional perde seu propósito, já que não é mais possível usá-lo como meio de determinar o avanço ou não dos alunos ao ano (série) seguinte.

Atualmente, a fragmentação do trabalho docente também atinge a avaliação dos processos de ensino. A cada início de ano, novas avaliações são realizadas pelos professores para que possam conhecer as turmas, seus avanços e necessidades, sem dar continuidade às avaliações feitas nos anos anteriores. Rompe-se a cada início de ano letivo o processo de aprendizagem traçado pelos alunos.

Apesar de um entendimento ainda superficial de muitos professores em relação à avaliação inserida no regime de ciclos, também se notaram mudanças a partir do atual contexto das escolas públicas. Não é possível manter as mesmas práticas usadas anteriormente, porque a estrutura do sistema mudou e não há como ignorar a presença de alunos com diferentes ritmos de aprendizagem nas salas regulares. Percebeu-se que a visão contruída pelas docentes sobre a avaliação dentro de um contexto de educação em ciclos vem se alterando. Elas reconhecem a importância de avaliar os alunos para o redirecionamento das atividades, centrando sobre eles o ritmo de tratamento dos conteúdos e a forma de abordá-los.

A avaliação, como indicador de avanços e limitações dos alunos, é realizada por meio de sondagens e da observação dos alunos em atividades em sala. No dia-a-dia as professoras realizam avaliação continuada, por meio de exercícios passados no caderno, em discussões em sala, atividades em grupo etc. Dessa forma, muitas vezes, sem que os alunos percebam que estão em uma situação de provação, as professoras avaliam seu desempenho. No entanto, a realidade mostra também que, para as docentes, é difícil desvencilhar-se de modelos mais tradicionais de avaliação como provas formais dadas em determinados períodos do ano letivo.
Observou-se que o conhecimento cotidiano que o professor adquire sobre o aluno tem sido considerado um dado importante na atribuição de conceitos e principalmente no replanejamento das atividades. Énecessário, no entanto, ponderar as implicações desses julgamentos e de que forma o juízo de valor que o professor constrói sobre seu aluno pode, de forma negativa, influir sobre o investimento que o docente demandará em relação as suas necessidades.

De forma geral, as professoras mostram empenho em reverter o quadro de defasagem encontrado. A comunidade escolar, com o passar dos anos, foi conhecendo melhor o novo regime limitando a muitos docentes a possibilidade de manter uma avaliação de aprendizagem em moldes mais tradicionais, como objetivo de estimular os alunos a estudarem, pois esses já sabem que vão "passar de ano" inevitavelmente em determinados anos do ciclo.

Percebe-se que o tema da avaliação ainda tem muitos pontos a serem superados. Essas mudanças dependem claramente de uma melhor formação e problematização do tema nos cursos de formação e dentro das escolas. Apesar de um entendimento ainda limitado sobre possíveis inovações no processo de avaliação dos alunos e a falta de condições observadas na escola, também é possível afirmar que a avaliação tem se transformado em um importante instrumento para detectar problemas e propor melhorias a ação docente.

\section{Indisciplina}

Com a adoção do regime de ciclos, alteraramse aspectos importantes da cultura escolar, já instituídos no regime seriado e que até hoje parecem enraigados no interior da escola. A inclusão de um maior número de alunos proporcionado pelas mudanças no sistema ampliou a diversidade da clientela atendida nas escolas, trazendo com ela problemas antes não enfrentados.

Com a reprovação, os professores tinham como uma de suas funções principais promover e reter os alunos ao final de cada ano letivo, de acordo com os resultados das avaliações aplicadas e o rendimento apresentado por elas. Com a adoção do regime de ciclos e a flexibilização dos tempos 
escolares, essa lógica centrada na reprovação, tanto para o estímulo aos estudos como para a inibição da indisciplina, perdeu seu sentido sem ter sido realizado um trabalho direcionado à comunidade escolar, incluindo os próprios professores, que auxiliasse na reflexão desse novo contexto e o levantamento dos encaminhamentos necessários para enfrentá-lo.

A indisciplina sempre existiu na escola mesmo no regime seriado, mas ela vem se configurando de uma nova forma no atual sistema. A inclusão de alunos de diferentes procedências ea permanência deles na escola têm originado o desinteresse pelos estudos, já que não vêm sentido num regime que desobriga a obtenção de bons conceitos (notas) como forma de avançar de um ano a outro.

As professoras afirmam que a motivação "caiu" muito com a adoção dos ciclos e que é necessário trazer constantemente atividades novas e dinâmicas para a classe, no sentido de atrair a atenção dos alunos aos estudos, estimulando a vontade de aprender, embora nem sempre consigam.

Nesse sentido, muitas delas criam projetos diferentes de trabalho e buscam, no atendimento das dificuldades individuais dos alunos, o estímulo para que sintam que são capazes de avançar dentro de suas possibilidades. Há um conflito claro entre o modelo de aluno que se espera ter, com um nível de ensino apropriado a sua faixa etária, e a diversidade de alunos que frequentam hoje as salas de aula.

Uma fala recorrente entre as docentes é a importância e, em contrapartida, a ausência de participação das famílias na vida escolar do alunos. Isso faz com que, segundo elas, os responsáveis não respondam às convocações quando chamados, e os alunos sintam que não têm limites dentro da escola.

Observou-se que existem poucos espaços de participação dos pais na escola e que esta não tem adotado a linguagem e os meios mais eficazes de estabelecer um diálogo mais próximo com as famílias.

A relação família-escola é de um incontestável distanciamento. Busca-se hoje superá-lo através de transformação no sistema de ensino e do aumento na participação da família para fazer face às tensões e insuficiências existentes. No entanto, é preciso ver a forma como a escola "entra" no domínio familiar; as exigências que se colocam às famílias, as informações de que estas dispõem com respeito à escola e quais são suas fontes. (GUSMÃO, 1997, p.176).

São muitos os fatores que geram a indisciplina, e o que se configurou após a implantação dos ciclos é o surgimento de uma nova realidade e, com ela, novos problemas. Essas questões demandariam a ampliação da discussão em torno das relações de poder na escola e os objetivos que propõem os ciclos. Conscientes do sentido dado ao ensino nesse contexto, pais, profissionais e alunos poderiam traçar um melhor caminho para o estudo e para a convivência mútua no ambiente escolar.

\section{Formação docente}

Analisando estudos que descrevem o impacto da implantação dos ciclos na rede pública municipal de São Paulo, percebe-se que os professores tinham no momento de sua implantação visões distintas sobre o que vinha a ser essa nova modalidade de ensino (JACOMINI, 2002). Muitos desconheciam como seriam os encaminhamentos para a concretização desse novo regime. Apesar do material de apoio divulgado nas escolas e das palestras realizadas durante o processo de implantação, as professoras revelaram ter muitas dúvidas sobre como concretizar os ciclos na prática.

As políticas educacionais que propõem mudanças diretamente ligadas à prática pedagógica, geralmente sofrem um descompasso muito grande no seu processo de implementação porque não se trata apenas de compreender mas, principalmente, de mudar a prática, e isso não ocorre de maneira uniforme. Embora incidindo sobre um conjunto de profissionais que possuem aspectos comuns em sua atuação, há muita diversidade em termos de formação e compromisso; por isso, 0 entendimento e a incorporação se dão de forma muito diferenciada [...] (JACOMINI, 2002, p. 215).

Hoje esse parece ser um problema ainda não solucionado e que tampouco tem sido o foco dos materiais e encontros promovidos pela SME atualmente.

Por meio das entrevistas, percebeu-se que a formação inicial das professoras não contemplou a reflexão de como viria a ser sua atuação 
no regime de ciclos. Segundo as docentes, o tema não foi discutido nos cursos, assim como não houve a problematização de como seria o trabalho docente inserido nesse contexto.

Partindo para a formação contínua, nota-se que os espaços instituídos dentro das escolas, nos períodos de horários coletivos, não vêm cumprindo seu papel formador no que tange à abordagem e ao estudo do tema. O que se notou no ano da pesquisa foi uma grande ênfase ao problema da alfabetização dos alunos, em especial do $1^{\circ}$ e $4^{\circ}$ ano.

Os cursos oferecidos pela prefeitura e que são feitos fora do horário de trabalho têm despertado o interesse de parte das professoras. Sua participação depende basicamente do interesse das professoras e a disponibilidade de tempo em realizá-las. Esses cursos seriam melhor aproveitados pelos docentes se pudessem ser realizados nos horários já disponíveis da escola e não como evento complementar já que muitos professores trabalham em mais de uma escola e acumulam outras funções, o que Ihe impossibilita dedicar mais de seu tempo livre ao trabalho.

Notou-se uma relação direta entre o entendimento mais apurado que algumas professoras tinham sobre os ciclos e a participação em cursos de formação oferecidos ou não pela prefeitura. Mesmo que os temas dos encontros não sejam expressamente os ciclos, o tema acaba sendo abordado nesses eventos de forma indireta, quando se discutem as possibilidades de trabalho em um ambiente ciclado. Essa possibilidade de incrementar a formação não deveria ser facultativa já que existem espaços próprios para que ocorram dentro das jornadas dos docentes.

Há casos observados de professoras que são declaradamente contra os ciclos, mas mostram mudanças na sua prática advindas da necessidade de atender melhor aos alunos incluídos hoje nas salas de aula. Seguramente, se elas pudessem participar de momentos de discussão e formação de forma mais produtiva, diferente do que vêm ocorrendo nos atuais horários coletivos, poderiam melhorar a sua atuação e atendimento dos alunos.

No entanto, também se observou que os horários coletivos eram usados como espaço para reflexão sobre a prática, sempre que não eram direcionados com atividades desconectadas da realidade e dos problemas enfretando pelos docentes. Naturalmente as professoras usavam esses momentos para troca de materiais e experiências.

O regime de ciclos trouxe com ele diferentes questões a serem interpretadas e superadas pelos docentes. Sem uma orientação mais específica sobre como realizar esse trabalho, os docentes se veem diante de uma realidade que exige respostas para questões vitais dentro do trabalho cotidiano. Tardif (2002, p. 49-50) trata da atitude docente em uma realidade que demanda a interpretação e a tomada de decisão:

Ela é realizada concretamente numa rede de interações com outras pessoas, num contexto onde 0 elemento humano é determinante e dominante e onde estão presentes símbolos, valores, sentimentos, atitudes, que são passíveis de interpretação e decisão, interpretação e decisão que possuem geralmente, um caráter de urgência.

Seria importante que os horários coletivos pudessem conciliar os saberes já construídos pelas professoras e as teorias advindas dos estudos realizados sobre prática docentes, ciclos e demais temas, tornando esse espaco atrativo e significativo. Assim, seria possível realizar uma formação condizente com o trabalho já feito pelas professoras e rico ao proporcionar melhorias qualitativas no processo de ensino.

\section{Prática em sala de aula}

Em entrevista com as professoras notou-se que, mesmo algumas discordando da implantação dos ciclos, muitas mostram mudanças em suas práticas como forma de adaptarem seu trabalho à atual estrutura criada. Essa transição foi essencialmente motivada pela existência de alunos com diferentes níveis de aprendizagem nas turmas. Muitas delas não reconhecem essas mudanças, afirmando que trabalham da mesma forma que o faziam no antigo regime. O fato é que as transformações sofridas nas práticas foram inevitáveis, já que a lógica do ensino atualmente funciona de acordo com outra clientela atendida, outra estrutura educacional, outras prioridades e outros objetivos.

Durante a entrevista, Helena parece ser enfática ao afirmar que não concorda com os pressupostos e as práticas preconizadas a partir 
da implantação dos ciclos na rede. No entanto, revela que tem produzido formas de atender aos alunos, ainda que seus "métodos" possam gerar críticas entre os educadores.

[0 trabalho diferenciado] Existe, mas tem que fazer de tal forma que 0 aluno não sinta que está sendo diferente 0 dele e o de outra criança. Por exemplo: vou dar uma conta de multiplicação. Passo na lousa e passo umas contas simples e outras difíceis. Se ele não conseguir fazer as difíceis, mas conseguir fazer as mais fáceis, eu elogio ele porque ele tentou. Ele vai corrigir, vai ver 0 que ele conseguiu fazer $\mathrm{e}$ daí ele vai tentar. Então falo: "Parabéns, você conseguiu! Agora vamos prestar mais atenção nas próximas contas". Mas sem rotular: "Você não sabe nada. Você é diferente das outras crianças". (Helena, professora do $4^{\circ}$ ano).

A falta de participação em cursos e eventos sobre o ensino no contexto dos ciclos parece ter criado em Helena uma barreira ainda difícil de ser transposta. Ela não se sente convencida de que o regime de ciclos pode ser adequado aos seus alunos. No entanto, não se mostra confortável diante das dificuldades das crianças e isso faz que sua prática sofra mudanças, ainda não perceptíveis para ela própria, mas que certamente já dão frutos entre seus alunos.

Essas mudanças acontecem numa combinação difícil entre as convicções das docentes sobre como se deve ensinar e a constatação das necessidades surgidas a partir de um novo contexto, mostrando que as professoras não estão estagnadas diante dos problemas surgidos. Jacomini (2002, p. 73) afirma que "a prática pedagógica acontece num movimento desigual e combinado, ou seja, combina novos e velhos elementos num contexto que pode ser caracterizado como de ruptura com o velho e a construção do novo".

Um ponto importante a se considerar é a criação de atendimentos diferenciados por conta dos diferentes níveis de aprendizagem dos alunos e suas dificuldades, como forma de "recuperar" as defasagens em seu percurso escolar. Para tanto, são realizadas atividades mais adequadas a esses níveis e que buscam tratar das necessidades dos alunos.

As professoras reconhecem que esse trabalho é realizado dependendo da disponibilidade de tempo e condições para sua efetivação. O grande número de alunos por sala, a carência de auxílio da coordenação pedagógica, os problemas na formação inicial e contínua, a fragmentação do trabalho docente são alguns fatores que dificultam esse trabalho.

Outra estratégia usada é o atendimento dos alunos por grupos e a realização das atividades gerais e específicas como forma de facilitar o atendimento e fazer com que os alunos possam avançar conjuntamente, mediante $\mathrm{O}$ compartilhamento de dúvidas e buscas de soluções entre alunos e professor.

A realização de sondagens e outras formas de avaliação diagnósticas também se mostraram práticas cada vez mais importantes e frequentes nas salas de aula, possibilitando aos professores identificar as dificuldades e os avanços da turma e propor intervenções.

As docentes também revelaram que buscam recursos para que as aulas se tornem mais atrativas, fazendo uso de dinâmicas, jogos e outros artifícios que possam despertar a motivação dos estudantes e auxiliar no tratamento do conteúdo das aulas. Segundo elas, o interesse dos alunos é o grande indicativo de redirecionamento das atividades. Também afirmam que buscam tratar de temas cotidianos, tocando, muitas vezes, em situações trazidas por eles próprios. O trabalho com a autoestima e a abordagem de assuntos de interesse dos alunos constituem uma preocupação de algumas professoras, já que elas notaram o valor dessas experiências para despertar a atenção dos estudantes, tornando as aulas mais atrativas e significativas.

Da perspectiva da organização escolar e da metodologia pedagógica, a escolarização de alunos/as heterogêneos estabelece a importância de que os professores/as atendam a grupos com uma grande variedade interna, na qual essas diferenças individuais são observadas em termos de interesses, ritmos de aprendizagem, predisposição para aprender, apoio familiar, etc. [...] A heterogeneidade estabelece para professores/ as e escolas a necessidade de considerar estratégias organizativas e didáticas para abordar: pontos de partida diferentes dos alunos/as frente aos conteúdos, necessidades e interesses diferentes, peculiares intensidades de esforços requeridos para cada aluno/a. (GIMENO SACRISTÁN; PEREZ GÓMEZ, 1998, p.187). 
Essas transformações, ainda que pequenas diante dos propósitos de um ensino em ciclos, mostram que há possibilidades de maiores mudanças na rede, revelando um potencial transformador entre essas professoras que lutam diariamente contra a falta de condições de trabalho, recaindo sobre elas, após a introdução dos ciclos, a responsabilidade de aprimorar sua prática e atender a diversidade de alunos.

\section{Considerações finais}

Mediante o estudo feito acerca da postura de professoras do ensino fundamental I em relação ao regime de ciclos implantado na rede pública municipal de São Paulo, é possível constatar que, a despeito de algumas pesquisas realizadas na área, são encontradas importantes mudanças na prática e reflexão docentes.

Conclui-se que as transformações reveladas no interior do cotidiano escolar advêm principalmente das mudanças estruturais trazidas com os ciclos, fazendo com que a lógica da reprovação perdesse sentido para professores, alunos e pais. Outro fator importante é a inclusão de alunos com diferentes ritmos de aprendizagem nas salas regulares e a garantia de realização de seu percurso escolar ao que corresponde o ensino fundamental. A partir desse novo contexto, as professoras viram-se diante da necessidade de reconstruir antigas práticas, a partir de um processo difícil que combina suas próprias convicções e a realidade apresentada nas escolas, efetivando ações que buscam proporcionar um ensino de melhor qualidade.

Essas mudanças nem sempre estão em relação direta com a concordância dessas docentes em relação ao regime de ciclos. Diante disso, nota-se que o compromisso assumido por elas é com a realização do seu trabalho no sentido de alcançar a aprendizagem dos alunos.

Entre os problemas observados, constatam-se falhas na formação inicial e contínua, fazendo com que o tema dos ciclos não ganhe o espaço devido nos cursos oferecidos e nas discussões realizadas nasescolas. Osmomentos deformaçãopromovidos pela prefeitura também parecem não considerar os problemas enfrentados nessa estrutura como tema a ser discutido e aperfeiçoado.

A falta de condições oferecidas nas escolas faz com que a fragmentação do trabalho pedagógico seja um problema que afeta em muitos aspectos a ação docente. Assim, os esforços percebidos no sentido de aumentar a qualidade do ensino oferecido têm partido muitas vezes da iniciativa individual das docentes. Por outro lado, elas recorrem a pequenos grupos, em horários não direcionados ao trabalho coletivo, para expor os problemas enfrentados e buscar soluções comuns, a partir de suas próprias experiências.

A pesquisa aponta que existem caminhos possíveis para a melhoria do ensino no regime de ciclos. Essas melhorias passam basicamente por mudanças nas condições de trabalho, incluindo o aperfeiçoamento do uso dos espaços coletivos da escola para uma formação que considere o percurso já feito e que possa subsidiar as reflexões acerca do trabalho das docentes no que tange ao planejamento curricular, às relações de poder, à relação com as famílias, à avaliação e às metodologias adotadas na escola. A principal contribuição desta investigação parece ser o de constatar as mudanças na postura de docentes e seus intentos na busca por soluções para a efetivação de uma educação de maior qualidade. 


\section{Referências}

AMBROSETTI, N. B. Ciclo Básico: o professor da escola paulista frente a uma proposta de mudança. Dissertação de Mestrado (Educação). São Paulo: PUC-SP, 1989.

ANDRADE, I. R. Ciclo básico: da proposta transformadora de alfabetização à realidade de sua prática. Dissertação de Mestrado (Educação). Campinas: UNICAMP, 1992.

AZANHA, J. M. P. Educação: temas polêmicos. São Paulo: Martins Fontes, 1995.

BARRETTO, E. S. S.; SOUSA, S. Z. (Coords.). Estado do conhecimento: ciclos e progressão escolar (1990 2002). São Paulo: FEUSP, 2004.

O projeto político - pedagógico nas escolas com ciclos. Difusão de idéias, São Paulo, mar. 2007.

FRANCO, C. (Org.) Avaliação, ciclos e promoção na educação. Porto Alegre: Artmed Editora, 2001.

FREITAS, J. C. de. Cultura e currículo: uma relação negada na política do sistema de progressão continuada no estado de São Paulo. Tese de Doutorado (Educação). São Paulo: PUC-SP, 2000.

FREITAS, L. C. Ciclos, seriação e avaliação: confrontos de lógicas. São Paulo: Moderna, 2003.

. A avaliação e as reformas dos anos de 1990: novas formas de exclusão, velhas formas de subordinação. Educação e Sociedade, Campinas, v. 25, n. 86, p. 133-170, abr. 2004.

GUILHERME, C. C. F. 0 processo de avaliação no ciclo básico: concepções, práticas e dificuldades. Dissertação de Mestrado (Educação). São Carlos: UFSCar, 1998.

GUSMÃO, N. M. M. Abandono escolar: função da escola que temos? Contemporaneidade e Educação, ano II, n. 1, p.173-179, maio 1997.

JACOMINI, M. A. Uma década de organização do ensino em ciclos na rede municipal de São Paulo: um olhar dos educadores. Dissertação de Mestrado (Educação). São Paulo: FEUSP, 2002.

MACHADO, S. A. Ciclos escolares: um estudo na Rede Municipal de Ensino de São Paulo. Dissertação de Mestrado (Educação). São Paulo: PUC-SP, 2005.

MAIA, E.; CRUZ, N.; RAMOS, M. L. São Paulo: a experiência da gestão educacional na Secretaria Municipal de Educação no período 1989 - 1992. In: XAVIER, A. C. R. (org). Gestão Educacional: experiências inovadoras. Brasília: IPEA, 1995. p. 129-170 (Série IPEA, n. 147)

MAINARDES, J. A promoção automática em questão: argumentos, implicações e possibilidades. Revista Brasileira de Estudos Pedagógicos, Brasília, v.79, n.192, p. 16-29, maio./ago. 1998.

PERRENOUD, P. Os ciclos de aprendizagem: um caminho para combater o fracasso escolar. Porto Alegre: Artmed, 2004.

GIMENO SACRISTÁN, J.; PÉREZ GÓMEZ, A. I.. Compreender e transformar o ensino. Porto Alegre: Artmed, 1998.

SÃO PAULO (SP). Secretaria Municipal de Educação. Orientações Curriculares e proposição de expectativas de aprendizagem para o Ensino Fundamental: Ciclo I, SME / DOT, 2007).

SENA, G. O de; MEDEIROS, N. R. L. O sistema progressivo e suas consequências no Estado de Santa Catarina. Cadernos do CED [UFSC], Florianópolis, v. 1, n.1/2, p. 111 - 174, 1984.

TARDIF, M. Saberes docentes e formação profissional. Petrópolis: Editora Vozes, 2002.

VASCONCELLOS, C. S. Ciclos de Formação: um horizonte libertador para a escola no $3^{\circ}$ milênio. Revista de Educação AEC, Brasília, v. 28, n. 111, p. 83-95, abr./ jun. 1999.

Recebido em Fevereiro de 2009

Aprovado em Maio de 2009 